\title{
Environmental impact assessment based on a potential oil spill scenario: Eastern Black Sea coastal zone, Turkey
}

\author{
Ö. Acır $^{1}$, R. Aps $^{2}$, M. Fetissov ${ }^{2} \&$ M. Sert $^{3}$ \\ ${ }^{1}$ Petrako Oil \& Gas Exploration Ltd., Ankara, Turkey \\ ${ }^{2}$ Estonian Marine Institute, University of Tartu, Estonia \\ ${ }^{3}$ Turkish State Meteorological Service, Ankara, Turkey
}

\begin{abstract}
The coastal fishery made in the Eastern Black Sea coastal area satisfies the country's major demand for fish and seafood. The area has also attracted attention with the increasing international oil and gas exploration activities carried on recently. Large capacity tankers pass through this sea area to carry crude oil and petrochemical products while existing and planned hydrocarbon transportation pipelines increase the cargo traffic as well. Therefore the new environmental risks are threatening this region's ecosystem due to the potential events such as tanker accidents, well explosions or pipeline leaks. In this study, the off-shore oil spill scenario is modeled for the Eastern Black Sea area. Potential Incident Simulation Control and Evaluation System (PISCES 2) is used to simulate the spreading of the spilled oil. The following factors are taken into consideration in the mathematical model: 1) environmental parameters: coastline, field of currents, weather, wave height and water density, 2) physical properties of spilled oil: specific gravity, surface tension, viscosity, distillation curve and emulsification characteristics, 3) properties of spill sources. Results of the oil spill scenario modeling shows extremely negative environmental impact of the potential oil spill accident on the coastal zone of the Eastern Black Sea.

Keywords: environmental impact assessment, net environmental benefit analysis, Bayesian inference, oil spill simulation, Eastern Black Sea.
\end{abstract}




\section{Introduction}

Recent oil spill occurred in Gulf of Mexico in the summer of 2010 has been the worst oil related accident in history. The event resulted in 11 people killed, more than 4.9 million barrels of crude oil have spilled to the sea (more than 60,000 barrels per day) whilst 42,000 people worked with 7,000 boats and more than 100 airplanes attended the response operations [1]. Operating company and US officials estimated the cost of overall damages and claims that they may reach to USD \$20 billion in time as well. However this is not the only or unusual event that the world seas encountered. In US coasts only, there were 251 events reported in 1964-2009 where the amount of oil spilled to the sea is more than 260,000 barrels [2]. Besides US, such events also occur all around the world. Europe and Middle East regions are the other environmentally risk prone areas due to the heavy oil transportation traffic (Table 1).

Table 1: $\quad$ Major oil spills in Europe and the Middle East coasts [3].

\begin{tabular}{|l|c|c|}
\hline Country & Dates & Bbbl \\
\hline Spain & 2002 & 441,000 \\
\hline United Kingdom & 1996 & 504,000 \\
\hline United Kingdom & 1993 & 595,000 \\
\hline Spain & 1992 & 518,000 \\
\hline Italy & 1991 & $1,008,000$ \\
\hline Iraq & 1991 & $5,740,000$ \\
\hline Spain & 1989 & 560,000 \\
\hline Iran & 1985 & 490,000 \\
\hline Iran & 1983 & $1,820,000$ \\
\hline Greece & 1980 & 700,000 \\
\hline Turkey & 1979 & 715,000 \\
\hline Ireland & 1979 & 448,000 \\
\hline France & 1978 & $1,589,000$ \\
\hline Spain & 1976 & 700,000 \\
\hline Portugal & 1975 & 616,000 \\
\hline Iran & 1972 & 805,000 \\
\hline
\end{tabular}

As seen in Table 1, the only spill accident in Turkey occurred at 1979 where the oil tanker "Independenta" carrying crude oil from Libya to Romania, crushed into another cargo ship at the Bosporus, which resulted a big explosion. According to the records, 43 people in the ship died in this tragic event whereas the fire could not be deflated through 27 days [4].

For the last couple of years, the load on Turkish coasts due to hydrocarbon and petrochemical transportation has been increasing sharply. One of the main reasons is that off-shore Black Sea coasts have been more attractive for international oil and gas exploration activities [5]. On the other hand Eastern 
Black Sea coasts of Turkey provide the country's major fish and seafood needs [6]. Therefore new environmental risks are threatening this region's ecosystem due to the potential events such as tanker crashes, well explosions or pipeline leaks.

In this study, a scenario based oil spill is modeled for the off-shore Eastern Black Sea area while physical impact parameters of this event are simulated in special software. The long term wave statistics and oceanographic data sets were used for this purpose while the potential spill location is selected hypothetically (Figure 1). The scope of this study is to understand the nature and environmental effects of such a potential disaster and help local authorities to develop an action plan accordingly.

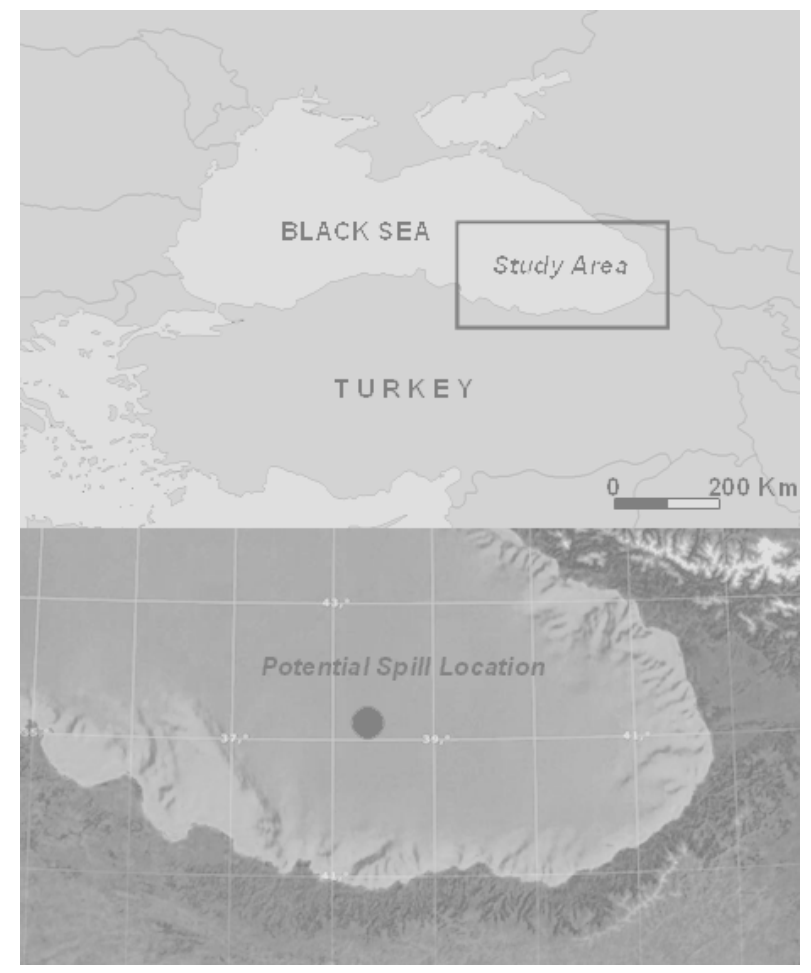

Figure 1: Study area with the position of the potential spill location.

\section{Material and methods}

PISCES 2 (Potential Incident Simulation Control and Evaluation System) of TRANSAS GROUP is used to simulate development of an oil spill incident scenario [7]. The PISCES 2 spill model simulates the processes in an oil spill on the water surface: transport by currents and wind, spreading, evaporation, 
dispersion, emulsification, viscosity variation, and interaction with the coastline (stranding or beaching).

In reality each accidental oil spill is unique in relation to the accident position, season and the accident time, the hydro-meteorological conditions, the type and the amount of the spilled oil. Therefore, the selection of scenarios is largely depending on the properties of the particular study. In our case two randomly selected scenarios were calculated with aim to get the general impression of the impact magnitude of the medium size oil spill under the most prevailing hydrometeorological conditions.

Accordingly, two oil spill scenarios were simulated with incident position: Lat $4203.934 \mathrm{~N}$, Lon $3822.110 \mathrm{E}$, spill rate: $4.9 \mathrm{t} / \mathrm{h}$, and the duration $120 \mathrm{~h}$ and $240 \mathrm{~h}$ respectively. Hydro-meteorological conditions during the scenario calculations in September 2010 are imported from Turkish State Meteorological Service forecast for 5 days: sea surface temperature $24^{\circ} \mathrm{C}$, air temperature $19-28^{\circ} \mathrm{C}$, wind direction N, NE, NW and force 2-9 knots, sea surface current Internal PISCES 2 Map of Surface Currents, direction SE, E, S and force 0.09 0.2 knots.

The Bayesian Belief Network (BBN) is constructed using the HUGIN RESEARCHER software. BBN is used to assess the general situation when answering the question: can the particular oil spill be combatted at sea using booms and skimmers? Current and wind speed in the oil incident sea area, predicted time interval of oil coming ashore are imported from PISCES 2 simulations. Mobilization time - the time needed for a ship/aircraft to arrive to an oil incident scene depends on the time the vehicle needs to get ready and the time needed to reach the location of the spill - is based on expert knowledge.

\section{Results and discussion}

\subsection{What are the expected drift, behaviour and fate of the spilled oil?}

Net Environmental Benefit Analysis (NEBA) is defined as a method to determine the most appropriate response option(s) in order to minimize the overall environmental impact of an oil spill $[8,9]$ and this method is often used for oil spill related risk assessment $[10,11]$. Immediately after notification of a pollution incident at sea, the NEBA is to be performed, and a quick decision is to be taken on the most appropriate response option(s). This decision is based on the following information [8]: 1) what are the expected drift, behavior and fate of the spilled oil, 2) can the oil spill be combatted at sea, and 3) is the oil threatening a sensitive resource?

According to the calculation results of the Scenario 1 presented in Figure 2 the 120 hours of continuous oil spill resulted in the $4359 \mathrm{bbl}(100 \%)$ of the spilled oil. Of that amount of the spilled oil the $2428 \mathrm{bbl}(58 \%)$ was floating, $1882 \mathrm{bbl}(39 \%)$ was evaporated and the rest of $50 \mathrm{bbl}(3 \%)$ was dispersed and emulsified. The average speed of the spilled oil was $0.21 \mathrm{~km} / \mathrm{h}$.

When getting on the sea surface, oil spreads out generating an oil film, which drifts in response to wind and currents. The simulation takes into account the 
following factors: 1) shore description, 2) representation of field of currents, 3) data on meteorological conditions: water temperature, wind direction/force, 4) spill parameters: time, place and kind of spill; amount and properties of the oil product.

For computation of oil movement under action of wind and currents, the slick travels in the current direction at the current velocity, and in the wind direction at a speed equal to $3 \%$ of the wind velocity. The resulting movement direction is geometrical addition of wind direction and current direction

It is necessary to assess the dimensions of the entire pollution area which oil is getting on from the scenario start time up to scenario end time. Figure 2 is showing the area where oil was present at any moment of time from the scenario start to the current model time moment, in grey color.

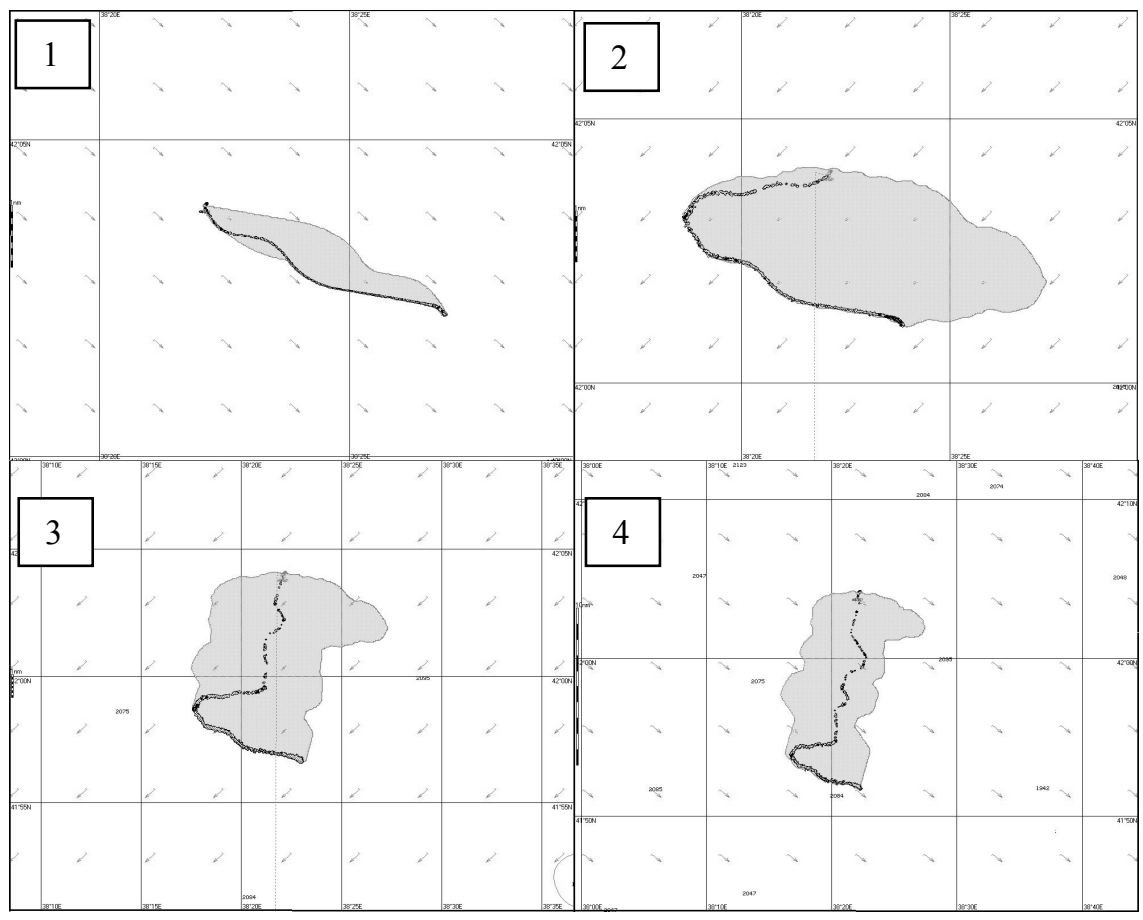

Figure 2: Display of pollution area for Scenario 1 after 1) $30 \mathrm{~h}, 2) 60 \mathrm{~h}$, 3) $90 \mathrm{~h}$ and 4) $120 \mathrm{~h}$ of simulated accidental continuous oil spill.

Scenario 2 calculations showed that (Figure 3) during 240 hours of continuous oil spill the total amount of spill resulted in $8560 \mathrm{bbl}(100 \%)$. Of that amount of the spilled oil the $3434 \mathrm{bbl}$ (42\%) was floating, $4482 \mathrm{bbl}(48 \%)$ was evaporated, $149 \mathrm{bbl}(4 \%)$ was dispersed and emulsified, and the $495 \mathrm{bbl}(6 \%)$ was stranded. Calculated slick maximum thickness was $14.4 \mathrm{~mm}$. Oil slick area (except footprint) was estimated $25 \mathrm{~km}^{2}$ and the pollution footprint $1792 \mathrm{~km}^{2}$. 
The average speed of the spilled oil was estimated at $0.58 \mathrm{~km} / \mathrm{h}$ and the total length of the polluted shoreline was estimated at $10 \mathrm{~km}$.

For the description an oil slick, the PISCES model uses Lagrangian approach, which is an effective technique of oil spill numerical simulation. The oil spill is represented by an ensemble of particles moving under the effect of wind and current [7]. The distinctive feature of the model is the extension of Lagrangian approach by introducing interactions between oil particles. This allows some essential lacks of the traditional Lagrangian methods to be compensated, and oil interaction with different kinds of natural and artificial barriers to be described in a satisfactory manner.

As it was already mentioned above, the movement of an oil slick is assumed to be two-dimensional and is resulting from transport by currents and wind, spreading and stochastic diffusion. Diffusion adds a random component to this movement.

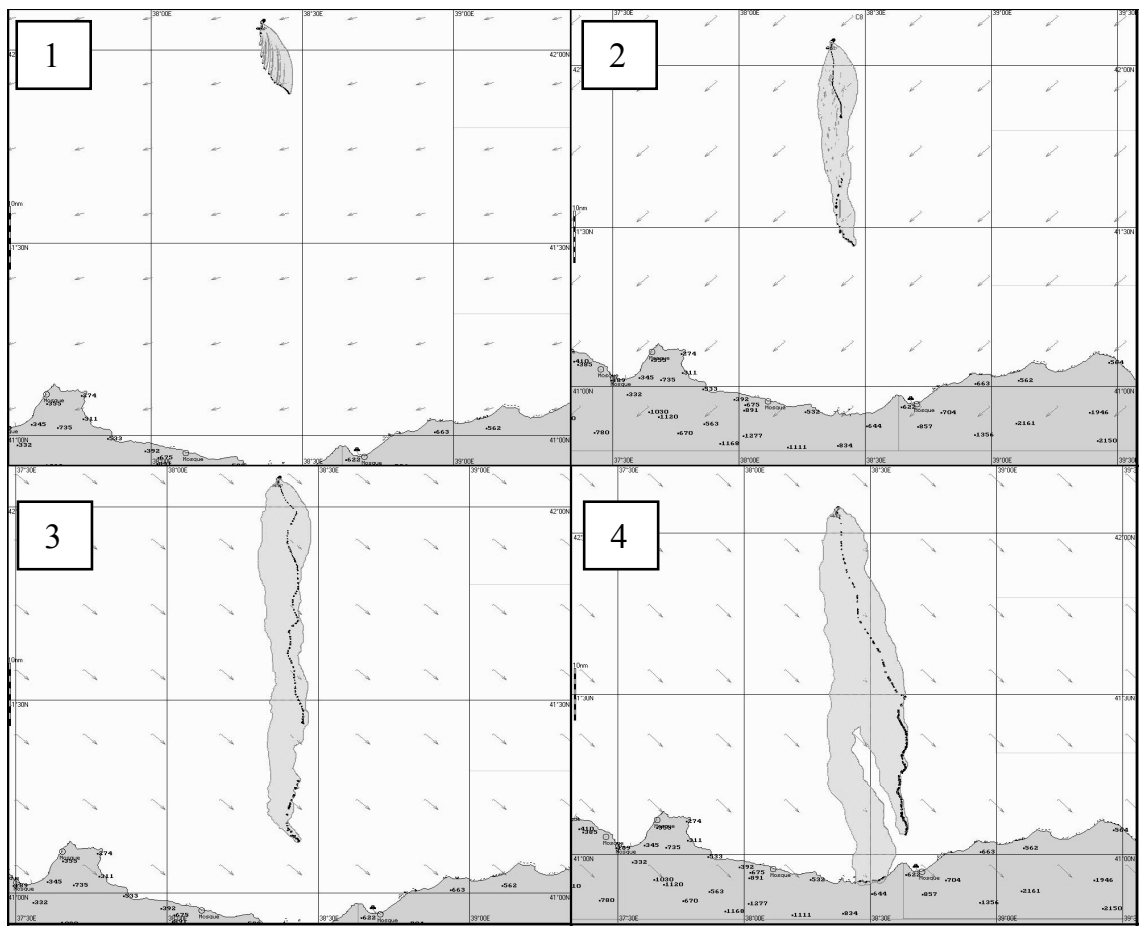

Figure 3: Display of pollution area for Scenario 2 after 1) $60 \mathrm{~h}, 2$ ) $120 \mathrm{~h}$, 3) $180 \mathrm{~h}$ and 4) $240 \mathrm{~h}$ of simulated accidental continuous oil spill.

\subsection{Can the oil spill be combatted at sea?}

According to [12] booms and skimmers are usually the first technique employed to remove the oil from marine environments but this technique can usually recover relatively small proportion of the spilled oil. At the same time, no boom 
is capable of containing oil against water velocities in excess of $0.58 \mathrm{~m} / \mathrm{s}$ acting at right angles to it. It is estimated that the critical current velocity for many crude oils and refined products ranges from $0.7(0.34 \mathrm{~m} / \mathrm{s})$ to 1.2 knots $(0.58$ $\mathrm{m} / \mathrm{s})$ while the 0.7 knots $(0.34 \mathrm{~m} / \mathrm{s})$ is accepted as a conservative estimate. Skimmers are used to remove oil from water and put it into storage tanks but how well a skimmer works depends on the type of oil spilled, the thickness of the slick and, the weather conditions. It is also estimated that the wave height of about $1.5 \mathrm{~m}$ is critical for the most types of booms to work efficiently.

Monthly average wave height and the wind speed in the sea area concerned in 2009 are presented in Figure 4.

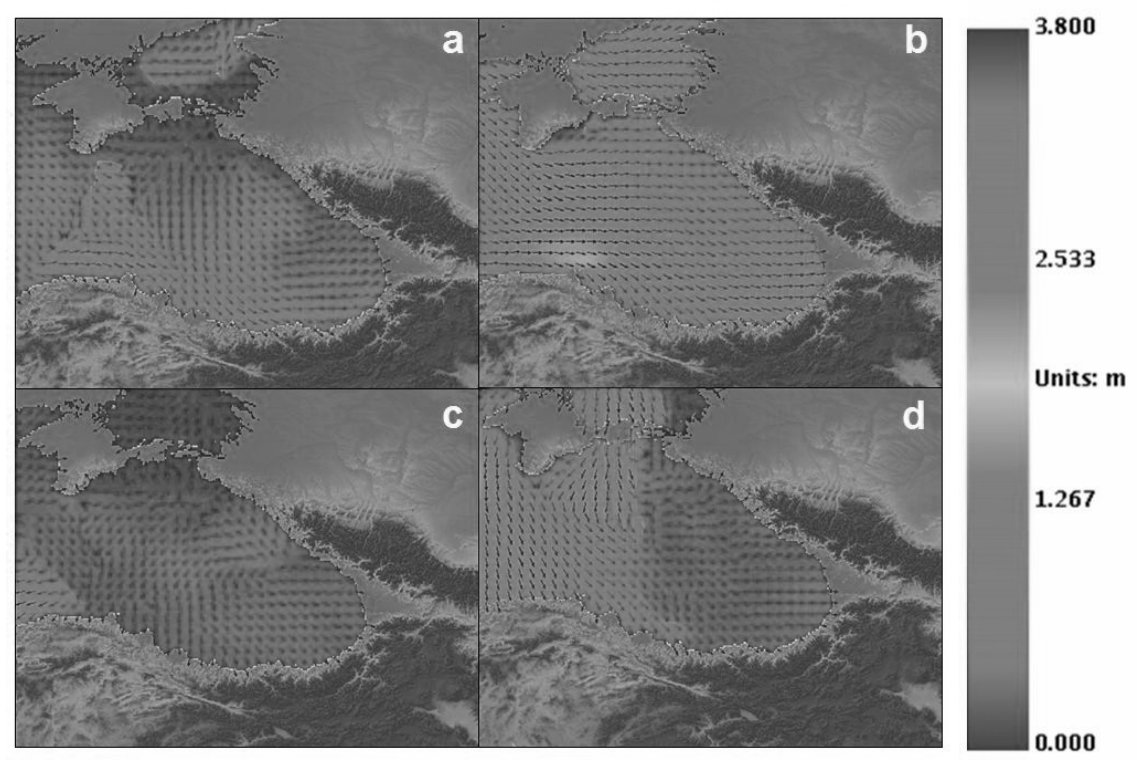

Figure 4: Monthly average wave height $(\mathrm{m})$ in the study area in 2009: (a) January (b) March (c) June (d) September.

Referring to the basic hydro-meteorological characteristics of the sea area concerned (Figure 4 and 5) it is concluded that in general there are quite favorable conditions for the use of booms and skimmers in the case of accidental oil spill. The monthly average wave height in some parts of the study area was just about $1.5 \mathrm{~m}$ in March 2009 while in January, June and September the average wave height did not exceed $1 \mathrm{~m}$. The monthly average wind speed was the highest in March 2009 reaching in some parts of the study area speed of 24 knots $(12 \mathrm{~m} / \mathrm{s})$. At the same time the average wind speed in January, June and September was about 12 knots $(6 \mathrm{~m} / \mathrm{s})$. 


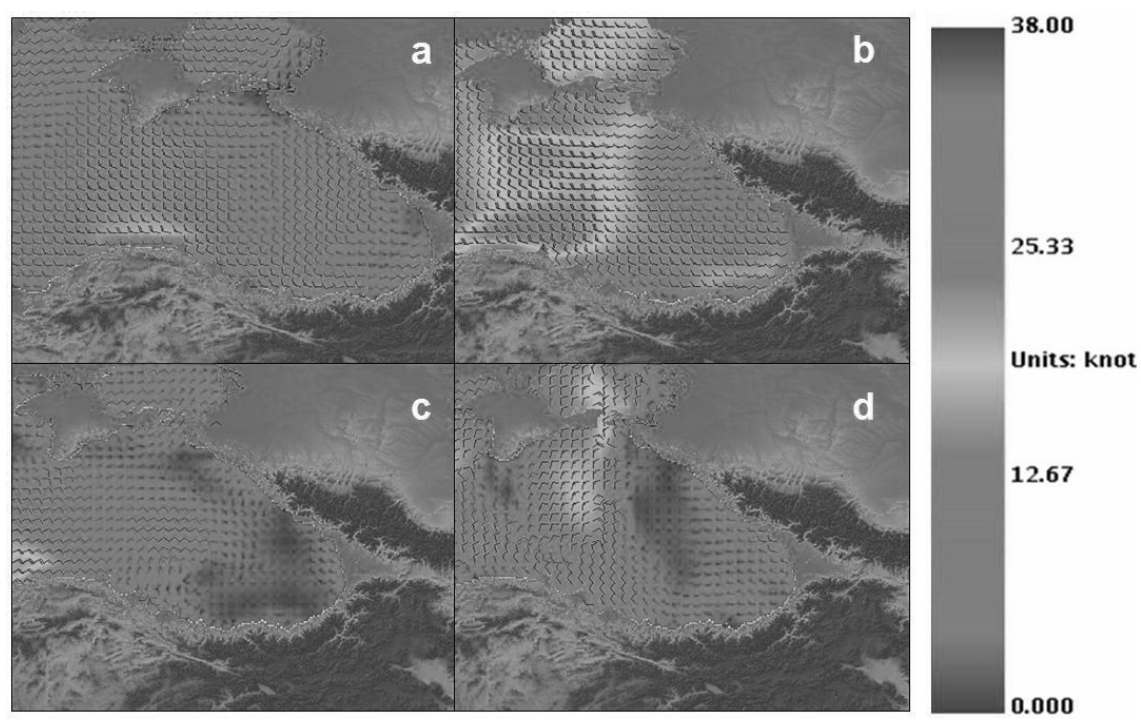

Figure 5: Monthly average wind speed (knots) in the study area in 2009: (a) January (b) March (c) June (d) September.

The $\mathrm{BBN}$ is constructed to assess general situation when answering the question: can the particular oil spill be combated at sea using booms and skimmers? Figure 6 communicates the basic conditions for efficient use of booms and skimmers.

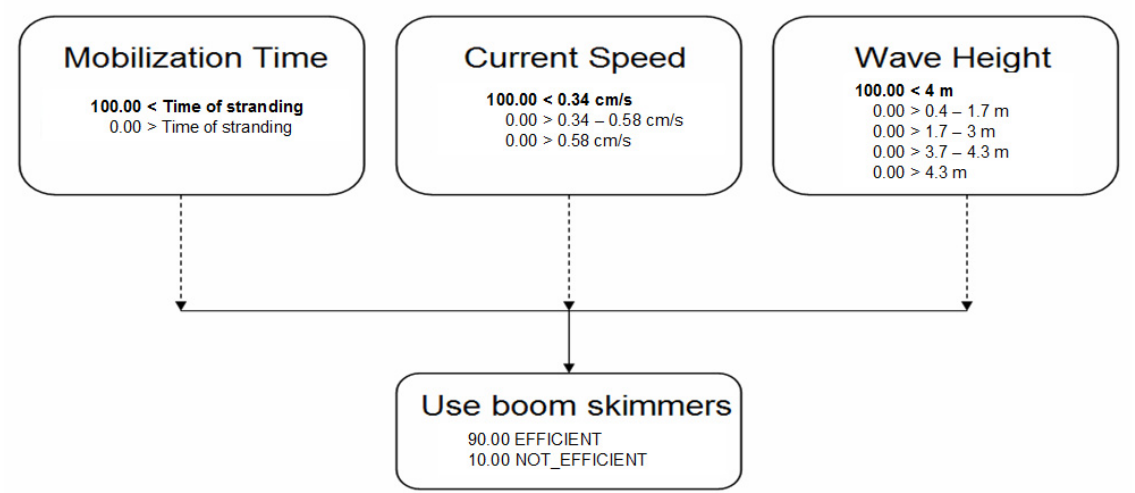

Figure 6: Low current $<0.34 \mathrm{~m} / \mathrm{s}$, and a wave height $<0.4 \mathrm{~m}$. mobilization time is less than time for oil to wash ashore. Use of booms and skimmers is efficient with probability of 0.90 , and inefficient with probability of 0.10 . 
However, if BBN simulations show that the use of the booms and skimmers is expected to be inefficient, it is almost impossible to prevent the oil from reaching ashore. In this case the advice on sensitive ecological resources likely to be impacted by the oil washing ashore is of critical importance in order to support decisions whether or not a response is necessary or what kind and extent of response is appropriate [11].

\subsection{Is the oil threatening a sensitive resource?}

Although both oil spill scenarios will have negative impact on the regional fishery activities, the second oil spill scenario will also have considerable impact on the coastline between Ordu and Giresun cities (Figure 7). This coastline is a center of tourism, sea food industry and transportation for about 1.5 million people [13].

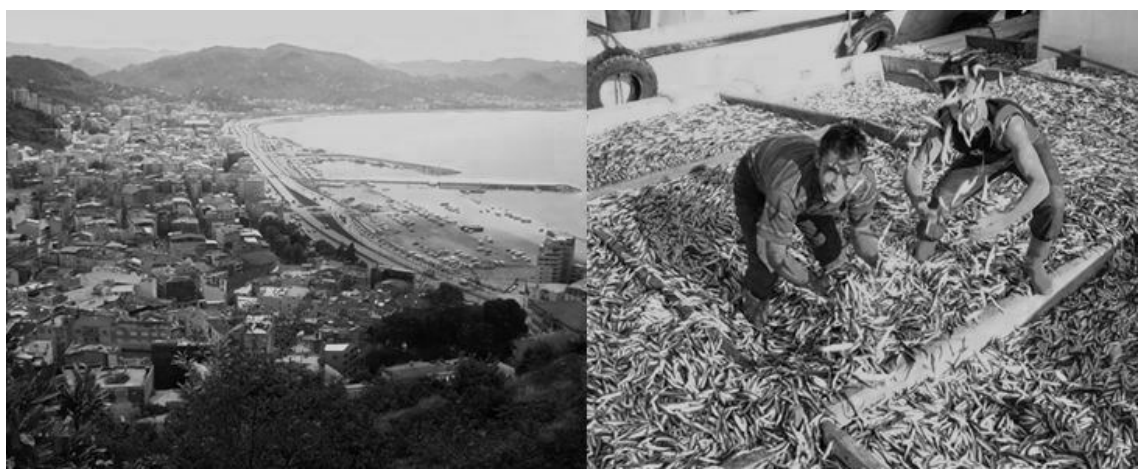

Figure 7: Giresun - Ordu coastline is hosting 1.5 million people where fishery is the main means of living.

In order to carry out the accidental oil spill related integrated risk assessment the further studies are planned. The Environmental Sensitivity Index (ESI) maps will be further developed as an integral component for oil-spill related contingency planning and response. According to NOAA [14] shoreline geology is ranked according to its physical characters, including relative exposure to wave and tidal energy, shore slope, substrate type, grain size, tidal elevation. Biological resources are segmented into seven components: marine mammals, terrestrial mammals, reptiles and amphibians, invertebrates, habitats and plants, birds and fish. Human-use resources are divided into four components: high-use recreational access locations, management areas, resource extraction locations, and archaeological/historical resource locations. However, according to [15] the ESI values and impacted coastline extent based environmental risk assessment results are not the only determinants of oil spill response management decisions, with the oil spill response managers considering many other factors as well. Legal mandates and political, social, and economic considerations may lead oil spill response managers to make decisions that are more or less protective 
because the implementation of some of the potential alternative decisions may be too expensive or not technically feasible.

\section{Conclusions}

Referring to the monthly average wave height and the wind speed values of the Eastern Black Sea area in 2009, it is concluded that in general there should be a quite wide window of opportunity for efficient use of booms and skimmers in the case of accidental oil spill.

However, if due to bad weather conditions the use of booms and skimmers is expected to be inefficient, it is almost impossible to prevent the oil from reaching ashore. In this case the knowledge on sensitive environmental and human use resources likely to be impacted by the oil washing ashore is of critical importance in order to support the efficient oil pollution response decisions.

In order to carry out the accidental oil spill related integrated risk assessment the further studies are planned. In particular, the ESI maps will be further developed as an integral component for oil-spill related contingency planning and response.

\section{Acknowledgements}

Authors would like to thank PETRAKO LTD, Turkish General Directorate of Petroleum Affairs and Turkish State Meteorological Service for their kind support during this study. We also thank the TRANSAS GROUP for the kind permission to use the latest edition of the PISCES 2 software. The study was supported by the Estonian Science Foundation through grant No 7609 and target financing program SF0180104s08.

\section{References}

[1] BP. Internal investigation report for Deep Water Horizon, p.183, 2010.

[2] US Bureau of Ocean Energy Management, Regulation and Enforcement. Spill summaries statistics 1970-2009. 2010.

[3] Etkin, D.S. Analysis of oil spill trends in the US and Worldwide, Proceedings of the International Oil Spill Conference, pp. 1291-1300, 2001.

[4] Göktepe, B.G. and Gönençgil, B. Environmental Safety of Oil and Gas Transportation Risks through the Turkish Straits, World Energy Council $18^{\text {th }}$ Congress, October 2001, Buenos Aires. 2001.

[5] GDPA. General Directorate of Petroleum Affairs. Bulletin of Annual Activities, 2000-2010.

[6] Yücel Ş. Social-Economic situation and fishery activities of the middle Black Sea region. Journal of Fisheries \& Aquatic Sciences, pp. 529-532, 2006. 
[7] Delgado, L., Kumzerova, E., Martynov, M. Simiulation of oil spill behavior and response operations in PISCES. Environmental Problems in Coastal Regions VI including Oil Spill Studies. Ed. C.A.Brebbia, Wessex Insitute of Technology, UK: WIT Press, pp. 279-292, 2006.

[8] IPIECA. Choosing spill response options to minimize damage - Net Environmental Benefit Analysis. IPIECA Report Series Volume 10, International Petroleum Industry Environmental Conservation Association, London, 20 p. 2000.

[9] Schallier, R., DiMarcantonio, M., Roose, P., Scory, S., Jacques, T.G., Merlin, F. X., Guyomarch, J., Le Guerroué, P., Duboscq, K., Melbye, A., Resby, J.L.M., Singsaas, I., Leirvik, F. NEBAJEX Pilot Project - Final Report. Royal Belgian Institute of Natural Sciences. 100 p. 2004.

[10] Aps, R., Fetissov, M., Herkül, K., Kotta, J., Leiger, R., Mander, Ü., Suursaar, Ü. Bayesian inference for predicting potential oil spill related ecological risk. In: M. Guarascio, C.A. Brebbia, F. Garzia (Eds). Safety and Security Engineering. UK: WIT Press, pp. 149-159. 2009.

[11] Aps, R., Herkül, K., Kotta, J., Kotta, I., Kopti, M., Leiger, R., Mander, Ü., Suursaar, Ü. Bayesian inference for oil spill related Net Environmental Benefit Analysis. In: C.A.Brebbia, G.Benassai, G.R.Rodriguez (Eds). Coastal Processes Southampton, Boston: WIT Press, pp. 235-246. 2009.

[12] Clark, R.B., Frid, C., Addrill, M. Marine pollution. Oxford UniversityPress, NY. 237 p. 2001.

[13] TUIK. Turkish Statistical Institute. Turkey's Statistical Yearbook. 2009.

[14] NOAA. Environmental Sensitivity Index Guidelines. Version 3.0. NOAA Technical Memorandum NOS OR\&R 11. 192 p. 2002.

[15] Aps, R., Sawano, N., Hamada, S., Fetissov, M. Bayesian inference in oil spill response management. In: Ed. Brebbia, C. Risk Analysis VII \& Brownfields V. UK: WIT Press, pp. 35-46. 2010. 